\title{
The Project Approach Meta-Project: Inquiry-Based Learning in Undergraduate Early Childhood Teacher Education
}

\author{
Adam S. Kennedy $^{1, *}$, Erin Horne ${ }^{2}$, Kelcie Dolan ${ }^{1}$, Cindy Herrera $^{1}$, Naomi Malutan ${ }^{1}$, Kathleen Noetzel $^{1}$ \\ ${ }^{1}$ School of Education, Loyola University Chicago, Chicago, Illinois, USA \\ ${ }^{2}$ The Frances Xavier Warde School, Chicago, Illinois, USA \\ *Corresponding author: akenne5@luc.edu
}

Received May 28, 2015; Revised June 11, 2015; Accepted June 17, 2015

\begin{abstract}
This article describes a case study involving the planning, phases, and outcomes of an exploration of the Project Approach led by four teacher candidates as part of an undergraduate early childhood teacher preparation program. Four undergraduate junior-level teacher candidates investigated the phases of the Project Approach during their junior year; this work took place during a 26-week learning module comprised of a seminar and part-time student teaching placement in a preschool setting. The candidates aligned the stages of their investigation with the phases of the Project Approach, which provided a framework complementary to that of action research, within which the candidates directed their own exploration of essential issues of early childhood pedagogy and curriculum. This investigation took place both at the Loyola and at a preschool in which the Project Approach was in use. Candidates assumed the role of the teacher and led actual projects with preschoolers; these served as culminating events for their project. In addition, at the conclusion of the module, candidates planned and hosted a session at which they shared documentation of their learning and outcomes of the investigation for an audience of university faculty and other teacher candidates. Candidates demonstrated an increased understanding of the Project Approach and a greater appreciation for its use with preschoolers. They also identified perceived advantages and challenges of implementing projects in various types of early childhood settings. Candidates exhibited high levels of collaboration with mentor co-teacher educators, and acquired knowledge and skills that informed their roles in guiding preschoolers through project planning and investigation during student teaching.
\end{abstract}

Keywords: Project Approach, teacher education, early childhood, inquiry learning

Cite This Article: Adam S. Kennedy, Erin Horne, Kelcie Dolan, Cindy Herrera, Naomi Malutan, and Kathleen Noetzel, "The Project Approach Meta-Project: Inquiry-Based Learning in Undergraduate Early Childhood Teacher Education.” American Journal of Educational Research, vol. 3, no. 7 (2015): 907-917. doi: 10.12691/education-3-7-15.

\section{Introduction}

Recent discussions about essential competencies for effective teaching have focused on 21st century skills [1], which teachers must instill in learners in order to prepare them for an increasingly complex society. These skills include critical thinking and problem solving, communication, collaboration, and creativity, each of which is recognized both essential and universal across the birth-to-grade 12 developmental continuum [12]. AACTE [1] presents these competencies as critical not only to teaching, but to the continued effectiveness of teacher education programs as well. As a result, AACTE and other scholars consistently state that teacher preparation programs must improve the quantity, depth, and comprehensiveness of authentic teaching experiences that address (among other skills) collaborative inquiry and problem-solving in a variety of learning contexts [7]. While inquiry and project-based teacher education activities have been frequently examined in such fields as nursing, mathematics education, and computer science, they have not been extensively examined in early childhood teacher education. In the work described here, undergraduate teacher candidates applied tools of investigation associated with the Project Approach (a form of project-based learning used with children) to study the approach itself, understand how it is used in preschool classrooms, and gain experience with it during extended field experiences.

\section{Literature Review}

The sections to follow provide an introduction to the Project Approach, including its features, benefits, and uses in higher education and early childhood teacher education in particular.

\subsection{The Project Approach}


The Project Approach is a child-centered approach to planning and organizing a wide range of learning activities $[13,15]$. It involves children in investigations of the world as they know and experience it, with support and guidance from teachers designed to reinforce learning based upon children's interests. Project work is inherently emergent and inquiry-based, with children's questions and discoveries steering the overall direction of activities that unfold over an extended investigation period. Nevertheless, teachers play an essential role in the process; an atmosphere of shared leadership between teacher and children is a key factor in the success of this approach. This combination of child-driven inquiry and focused activities opens the door to higher levels of intellectual involvement and challenge than the exclusive use of teacher-directed themed units, which require teachers to assume primary responsibility for sustaining children's interest and active exploration [13].

\subsection{Problem-based Learning and the Project Approach in Higher Education}

The use of project work adapted for the higher education setting aligns with the principles and philosophy of problem-based experiential learning, a frequently cited instructional approach in which learning occurs through active work on solving complex applied and practical problems (e.g., $[2,3,10,14])$. The roles of the instructor in problem-based learning include supporting and facilitating students' efforts to address complex problems, and connecting these efforts to appropriate learning objectives. Evidence suggests that this approach may effectively address content knowledge and encourage higher order thinking, in addition to increasing the intrinsicallymotivated problem-solving in which it is embedded (e.g., [23]). It has also been found to increase and students' sense of ownership over their learning (e.g., [19]), and their creativity in solving more complex, real-world problems, as well as holding promise for encouraging students' participation in communities of practice [9].

In a teacher education context, problem-based learning promotes the development of flexible and practical strategies (rather than rigid formulas) to address complex issues in teaching practice. Such instructional strategies accomplish this by promoting pre-service teachers' flexibility and higher-order thinking (e.g., [4]). These flexible approaches better equip teacher candidates to deal with the practical realities of teaching, and to grow as reflective practitioners [21]. Inquiry-based preparation may also present opportunities for more sophisticated and authentic collaboration than traditional classroom-based teacher education courses can provide. Some evidence already suggests that the Project Approach itself can be successfully integrated into university teacher preparation programs. Vasconcelos [24] for example, evaluated an interdisciplinary seminar in which higher education students in Lisbon were trained in the Project Approach during a week-long course integrated into instructional methods courses prior to student teaching. In this model, teacher candidates completed assigned readings about the Project Approach, viewed demonstration videos, and developed and presented demonstration projects to university faculty in preparation for a subsequent student teaching experience during which they implemented the
Project Approach. The seminar provided opportunities for meaningful assessment of candidates' skills, as well as a focus for ongoing critical reflection by both classroom teachers and teacher candidates [24]. Increased recognition of the importance of contextually-situated professional development was also cited as a universal benefit of the seminar.

Building upon this, Bullard and Bullock [5] used a week-long course on the Project Approach and the practices of preschool instruction in Reggio Emilia, Italy, as an opportunity to prepare pre-service and practicing teachers through simulations of project learning consisting of investigations centered on teachers' own questions and interests. Teachers selected project topics based upon elements of the natural outdoor environment surrounding the center in which the course was held. Participants reported increased appreciation for emergent learning and satisfaction with cooperative experiences that required them to place themselves in the role of an investigating child.

These studies share a similar structure consisting of coursework/training in which examples of children's projects were shared, followed by supervised individual and collaborative simulations of the Project Approach phases by pre-service and practicing teachers. In one case, adults conducted projects in which they took on the role of a child investigator, exploring topics and questions of their choosing). In the second example, adults developed hypothetical projects for potential use with children at a later time in their own work settings.

Prior research has linked the Project Approach to other methods of inquiry learning and supported its use in higher education. Additional studies focusing on early childhood teacher education have demonstrated benefits to preservice and practicing teachers. However, the university classroom has served as the context of these types of studies, with some relying on simulations conducted by adults. The present investigation uses some similar features from this literature by incorporating key elements of previous studies (including preparation in the Project Approach, practice in essential skills, and opportunities to apply those skills to projects). The unique feature of the present study is that it is embedded in: a) a year-long sequence or activities that mirrored the phases of the Project Approach itself; b) a field-based undergraduate teacher preparation program model; and c) direct experiences with young children as an authentic context for applying investigating the features of this approach.

\section{Methods}

The primary objectives of this investigation included increasing teacher candidates' appreciation for and understanding of the Project Approach, as well as their developmentally appropriate adult-child interaction in leading project work. In this section, information about the teacher preparation and FXW partner contexts will be shared, followed by a presentation of the phases of teacher candidates' investigation and examples of associated artifacts.

\subsection{The Context: Field-based, Urban Early Childhood Education Teacher Preparation}


Loyola University Chicago is a private Jesuit university located in Chicago, Illinois. Over the past three years, faculty in the School of Education at Loyola have engaged in a process of program redesign for all teacher preparation programs. Faculty and community partners (including schools, community agencies, museums, and child care centers) worked to transform the traditional, university-based, course-driven preparation model to a community-based model referred to as Teaching, Learning, and Leading with Schools and Communities, or TLLSC [22]. TLLSC consists of four years of field experiences guided by faculty in collaboration with community partners (such as those listed above) across Chicago; this continuum of field experiences was developed using a process of backward design [25], and guides novice teacher candidates to mastery of evidence-based practice over 4 years [18]. The TLLSC undergraduate program in Early Childhood Special Education (ECSE) was designed to prepare teachers to address the needs of diverse children from birth through age eight in inclusive urban settings. The ECSE program integrates traditionally separate areas of early childhood teacher education and leads to teaching licensure in early childhood with endorsements in ECSE and English as a Second Language from the Illinois State Board of Education [12], as well providing preparation necessary to obtain early intervention credentialing by the Illinois Department of Human Services, enabling graduates to work with the families of infants and toddlers with special needs.

In the redesigned ECSE program, eight semester-long field-based sequences are continuously supervised by early childhood faculty and practicing educators, with each sequence divided into shorter targeted modules (3 to 12 weeks in length); ECSE teacher candidates begin exploring birth-grade 12 settings in sequences 1-3, after which they spend sequences 4 through 8 exclusively in early childhood settings where community partners (Early Head Start/Head Start, public and private preschool and ECSE settings, public elementary schools, and other community agencies) offer experiences in a variety of inclusive and family-centered program models [12]. Partner sites emphasize best practices for young children, including DEC's Recommended Practices [8] for Early Intervention and Early Childhood Special Education.

It was within this context of teacher preparation redesign that the current investigation was conducted. It emerged as the focus of a pilot of preschool-based sequences that are now required for all candidates in the ECSE program. Extended field experiences made the project possible, since sufficient time (26 weeks total) was available in which to conduct it. During their third year of undergraduate preparation, four junior-level ECSE candidates spent the majority of one academic year in preschool-based sequences, supported by an accompanying seminar (as opposed to a traditional model in which clinical hours are attached to a course). This allowed for 10 weeks of in-depth exploration the approach, after which candidates spent a full semester applying learned knowledge and skills during a student teaching sequence.

The field-based module presented in this article shares several features with examples from prior research; for instance, this module began with study of the Project Approach followed by group and individual exploration.
Here, undergraduate teacher candidates engaged in background investigation (including relevant readings such as the work of Katz $[15,16]$, and Katz and Chard $[6,16,17]$. One full-time ECSE faculty member and one part-time clinical instructor guided the candidates as they conducted individual and group inquiry, and the candidates engaged in cycles of investigation and reflection throughout. The uniqueness of the approach described here stems from the contexts and experiences within which the instruction was embedded. In the present study, the Project Approach itself was the topic of investigation, and students' field experiences served as the everyday world in which they individually and collectively conducted their investigation. In what may be best described as a meta-project, candidates assisted with actual projects originating in the interests and questions of young children, and their teaching acts served as tools of their individual and collaborative investigation into the Project Approach.

\subsection{The Project Setting: The Frances Xavier Warde School}

As previously stated, a goal of this investigation was to increase not only knowledge of the Project Approach, but candidates' teaching skills as well. This goal could only have been achieved in a preschool with the capacity to support the Project Approach; in this case, teachers and administrators in the preschool program at the The Frances Xavier Warde School (FXW) allowed the candidates to be placed in classrooms where every teacher utilized the Project Approach. In keeping with the approach's philosophy and key stages, children at FXW (a private, Catholic preschool located in downtown Chicago) are guided to develop interests in many topics and themes and investigate these through long-term projects. Children's learning is inquiry-based, allowing for the integration of multiple developmental domains and learning standards as they learn from real-life, relevant experiences and research. Children ask questions to guide investigations and the direction of their study; they make decisions about activities, the ways in which they will investigate topics, and how their learning will be documented and shared/displayed.

Project learning was first introduced at FXW during the 2007-2008 school year. Teachers and administrators agreed that a theme-based curriculum had ceased to hold relevance to the lives of the children served by the school. Project learning appeared to hold greater promise because it supported children's natural higher level thinking, questioning and application skills. Teachers were initially trained by Lilian Katz; subsequently, new teachers were partnered with veteran teachers (who had become local experts in creating project-based learning experiences for children) in order to support their learning and facilitate implementation. Additionally, new teachers continued to receive support to attend conferences on project based learning to deepen their understanding and implementation of this strategy. The collaboration with Loyola's ECSE program opened the door to a new level of mentoring in inquiry-based learning, involving collaboration between pre-service and practicing teachers (who served as co-teacher educators alongside Loyola faculty). 


\subsection{The Project Approach Meta-project}

Table 1 presents the timeline for this project as described in the following sections. The entire project timeline unfolded over two sequences (a total of two 13week semesters); each week (or series of weeks) is presented with a description of the work that took place within.

Table 1. Project timeline

\begin{tabular}{|c|c|c|}
\hline \multicolumn{3}{|c|}{ Fall semester } \\
\hline Week & Project phase & University and field experiences \\
\hline 1 & & Introduction to Project Approach \\
\hline 2 & & Initial visit to the FXW School an \\
\hline 3 & 1 & $\begin{array}{l}\text { Decision to continue with the Pro } \\
\text { Topic webbing and initial questio }\end{array}$ \\
\hline $3-10$ & 2 & $\begin{array}{l}\text { Weekly field-based experiences } \\
\text { Refinement of initial questions } \\
\text { Identification of resources and me } \\
\text { Investigation of the Project Apprc }\end{array}$ \\
\hline 10 & 3 & $\begin{array}{l}\text { Midpoint debriefing sessions was } \\
\text { Video journal reflections } \\
\text { Observations and evaluation of ca } \\
\text { Consideration of additional culmi } \\
\text { Decision to continue with project }\end{array}$ \\
\hline \multicolumn{3}{|c|}{ Spring semester } \\
\hline Week & Project phase & University and field experiences \\
\hline 11 & 2 & $\begin{array}{l}\text { preschool student teaching placen } \\
\text { Revisiting and refinement of initi } \\
\text { Candidates continue investigation }\end{array}$ \\
\hline $11-25$ & 2 & $\begin{array}{l}\text { Co-teacher educators assume gre } \\
\text { responsibility for continuing and } \\
\text { Candidates lead students in Proje } \\
\text { Weekly student teaching seminar } \\
\text { Final video journal reflections }\end{array}$ \\
\hline 26 & 3 & $\begin{array}{l}\text { Presentations to faculty and new } \\
\text { Final debriefing }\end{array}$ \\
\hline \multicolumn{3}{|c|}{$\begin{array}{l}\text { The initial plan to explore the Project Approach in this } \\
\text { manner emerged from candidates' own enthusiasm and } \\
\text { curiosity. In preparation for their field-based sequence, } \\
\text { faculty and candidates attended an orientation meeting at } \\
\text { FXW, during which teachers and administrators explained } \\
\text { the school's philosophy, structure, and curriculum. Since } \\
\text { the Project Approach had been implemented in all FXW } \\
\text { preschool classrooms, time was set aside during this } \\
\text { orientation to introduce candidates to the approach and } \\
\text { answer questions about their prior reading. Teachers } \\
\text { described their experiences in implementing the Project } \\
\text { Approach in their classrooms, including visual } \\
\text { presentations illustrating projects they had completed with } \\
\text { children the previous year. These contained images of } \\
\text { preschoolers engaged in all phases of project work in } \\
\text { classrooms (topics included pizza, fish, fire trucks, and } \\
\text { washing cars) and participating in a range of culminating } \\
\text { events both on field trips and within the school. Following } \\
\text { this session, the candidates each visited one of the FXW } \\
\text { preschool classrooms for a half day. } \\
\text { Following this visit, faculty held a debriefing session } \\
\text { with the four candidates, during which they expressed } \\
\text { their heightened interest in the Project Approach, } \\
\text { excitement about the upcoming field experience, and new } \\
\text { questions about the approach and its relationship to early } \\
\text { childhood curriculum. Through discussion about these } \\
\text { experiences, it emerged that the initial classroom visits, } \\
\text { orientation meeting, readings, and in particular the teacher } \\
\text { presentations, had served as focusing events that could } \\
\text { drive candidates' upcoming experiences and shape them } \\
\text { as project-like investigations. At this point, faculty } \\
\text { members and candidates discussed and made the mutual } \\
\text { decision to attempt to embark upon this work as a meta- } \\
\text { project. }\end{array}$} \\
\hline
\end{tabular}
candidates to determine whether the Project Approach was itself an appropriate project topic. The group examined Katz and Chard's [17] criteria for the topics of children's projects in order to assess whether parallels could be drawn to adult learning and the needs of pre-service teachers. According to Katz and Chard, topics should meet four criteria: first, they must provide opportunities for investigators to understand their own experiences. The candidates determined that weekly applied reflective learning experiences met this criterion, and faculty members' continuous individual and group supervision of teacher candidates served as an opportunity to interpret experiences in a developmentally appropriate way. In fact, candidates' experiences would allow them to acting as both project learners and facilitators, providing a parallel set of experiences.

Next, appropriate topics should increase intensity of focus on phenomena that warrant investigation [17]. When applied to adult learning, this criterion represents the most difficult to address when simulations or hypothetical projects are used, since the adults must either play the role of a child or imagine what they might do as teachers. Here, however, the intention was for questions to continually emerge both from candidates' study of the Project Approach and from their facilitation with children engaged in actual projects. In this way, they would be focused on seeking answers to their questions through focused study and directly through intensely focused, guided acts of teaching.

Third, topics must support a range of skills and dispositions [16]. While a meta-project would provide opportunities for both for faculty and classroom teachers to model adult-child interaction, as well as for candidates to apply knowledge and improve their teaching skills, 
faculty determined that an appropriate assessment of these skills was lacking. An extensive universal clinical evaluation tool had been previously designed by School of Education faculty and used during observations of candidates' teaching, but this tool included only general items assessed independently of the curriculum or approach used. In this sense, it lacked a substantive connection to the Project Approach. Faculty subsequently adapted the assessment so that it incorporated language directly reflecting project work. Table 1 provides an example of one section of this instrument that includes revised skills related to the Project Approach. The instrument was used to evaluate candidates and provide feedback at the start, midpoint, and end of student teaching in weeks 11-25.

Table 2. Examples from teacher candidate evaluation tool with Project Approach adaptations

\begin{tabular}{|c|c|c|}
\hline \multicolumn{3}{|c|}{ Systematic and Organized Instruction/Intervention } \\
\hline \multicolumn{3}{|c|}{ Scale: 3=Target, 2=AccepTable 1=Unacceptable } \\
\hline 1 & $\begin{array}{l}\text { Observed activities are a part of a larger unit/project/goal and contribute to deepening children's conceptual } \\
\text { understanding, increasing skill, and/or developing independence }\end{array}$ & 123 \\
\hline 2 & $\begin{array}{l}\text { Activities use a variety of formats (e.g., play, routines, small group activities, inquiry approaches, and systematic } \\
\text { instruction) appropriate to their objectives. }\end{array}$ & 123 \\
\hline 3 & $\begin{array}{l}\text { Candidate builds upon prior knowledge and young children's experiences when introducing, leading, or expanding } \\
\text { upon new concepts and activities. }\end{array}$ & 123 \\
\hline 4 & $\begin{array}{l}\text { Candidate assumes roles that range from instructor, facilitator, and coach to audience in relation to context and } \\
\text { children's needs. }\end{array}$ & 123 \\
\hline 5 & Instruction responds to the varied cultures and languages of the classroom to enhance development/learning. & 123 \\
\hline 6 & Candidate explains how an observed instructional activity addresses IFSP/IEP goals for children with special needs & 123 \\
\hline \multicolumn{2}{|r|}{$\begin{array}{l}\text { Overall Rating of Coherence: Choose the mode of the ratings above. Exception: three or more ratings of ' } 1 \text { ' earn an overall } \\
\text { rating of ' } 1 \text { '. }\end{array}$} & 123 \\
\hline
\end{tabular}

Comments (Note examples/evidence of ratings, as well as explanation for any rating of 1 or 3 ):

Finally, project topics must provide opportunities for exploration and representation using a range of media. Faculty and the candidates agreed that this guideline directly applied to adult inquiry learning. During this investigation, the candidates would engage in fieldsituated exploration alongside teachers and children, using the diverse settings (including the local community) and media selected by preschoolers themselves. The diverse media used by teachers and children were, as a result, infused throughout.

At this point, project work began in earnest. The sections to follow are presented as a project, describing the ways in which candidates moved through the Project Approach phases by generating their own questions to investigate (through topic web development and class discussion in Phase 1), developing representations of their emerging learning (Phase 2), and planning culminating experiences that highlighted their learning (Phase 3).

\subsubsection{Phase 1}

Phase 1 (Weeks 1-3) took place during a ten-week university-based seminar that included weekly facultysupervised visits to FXW preschool classrooms. In preparation for their field experiences, teacher candidates completed readings from Helm \& Katz [13] which described the Project Approach and the use of projects with young children. They also examined and discussed published examples of projects. Faculty instructed candidates on curriculum maps and topic webs, after which they were assigned the task of creating and sharing individual webs about themselves, with their own names at the center.

Next, the candidates practiced developing thematic curriculum webs. The candidates chose what they believed to be developmentally appropriate preschool themes for these webs. Faculty and peer feedback was provided on both the themes and maps, and the group discussed potential benefits and limitations of teacher-developed themes. Figure 1 displays an example of a candidate's thematic web on rainforests; the candidates were able to draw the conclusion that rainforest is potentially a rich theme for the preschool classroom, but provided limited opportunities for active, hands-on exploration.

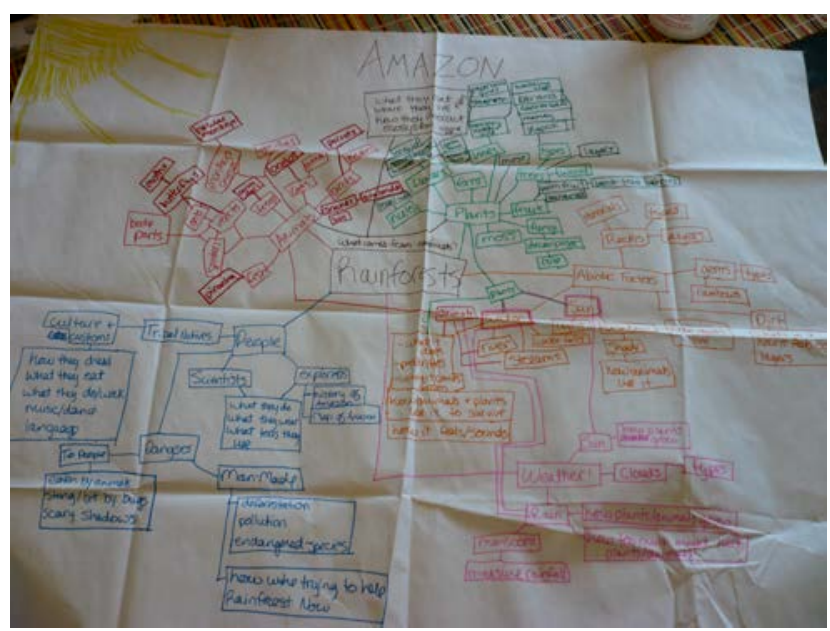

Figure 1. Example of a teacher candidate-created thematic web on rainforests

At this point, the difference between traditional themes and project topics was introduced. Faculty modeled examples of child-directed topic webbing and each candidate had the opportunity to lead a webbing simulation. They were each given a topic by their classmates and role-played the process of creating a web with children. The group engaged in discussion about the resources needed to investigate their themes and topics. As illustrated in Figure 2, these webs demonstrated the candidates' emerging understanding of the differences between unit-based curriculum/thematic webs and projectbased topic webs. Specifically, candidates explored the role of children and their surroundings in projects, which demonstrated, for example, that farms provided many more opportunities for investigation in the communities surrounding Chicago than would rainforests. The candidates also began to explore the process of developing topic webs while simultaneously observing webbing 
activities during their visits to FXW, where each candidate was placed in a different preschool classroom with two mentor teachers.

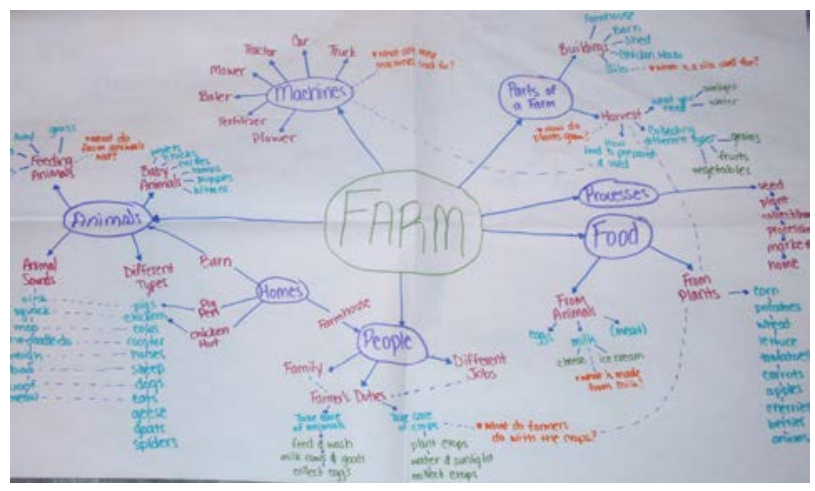

Figure 2. Example of a teacher candidate-developed topic web on farms

Candidates then began their own project by developing anticipatory topic webs about the Project Approach, integrating what they had learned from all of their prior experiences and information learned from readings and class activities. The candidates worked in pairs to identify central topics related to the Project Approach and collaboratively design webs around it with instructor support. This engaged students in the simultaneous roles of teacher and learner as they alternated roles within their pairs. Figure 3 to Figure 5 show students at work on these webs.

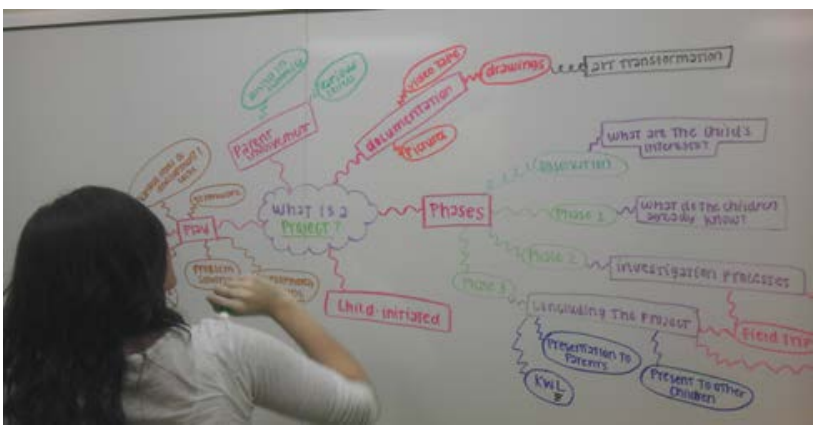

Figure 3. A teacher candidate collaborates on a topic web created around the question 'What is a project?'

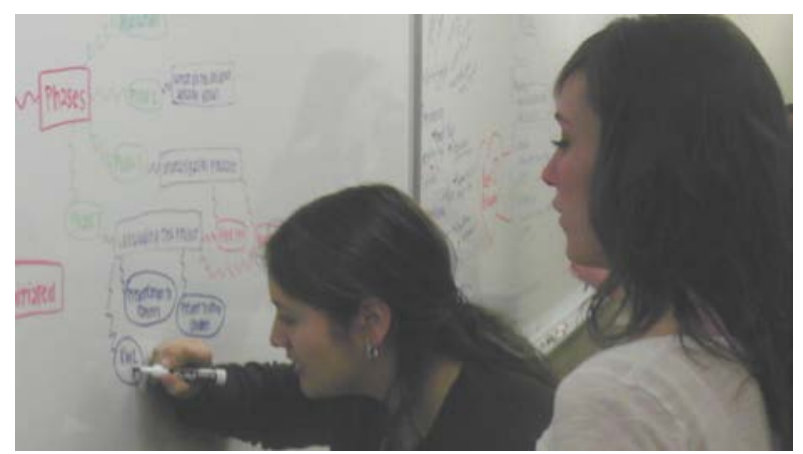

Figure 4. Candidates collaborate on their Project Approach topic webs

Next, the pairs of candidates came together to discuss map similarities and differences and integrate them into a single map. During this process, they identified questions to investigate; their list of initial questions is displayed in Figure 6. Candidates' questions expressed general curiosity regarding origins (Where did [the Project Approach] come from?), an interest in seeing more of the approach in action (Can we see this from beginning to end?) to more practical questions about how it works
(How do we move from...interests... to deciding to do a project...to choosing activities? What happens when a project fizzles out?). The questions also seem to indicate that students were connecting to and re-evaluating their prior knowledge regarding early childhood curriculum (What is its relationship to other approaches? What happens when no project is going on?). The question Why doesn't everyone use the Project Approach? was not only a reflection of their enthusiasm, but also of their desire to understand how decisions regarding curriculum are made in early childhood programs.

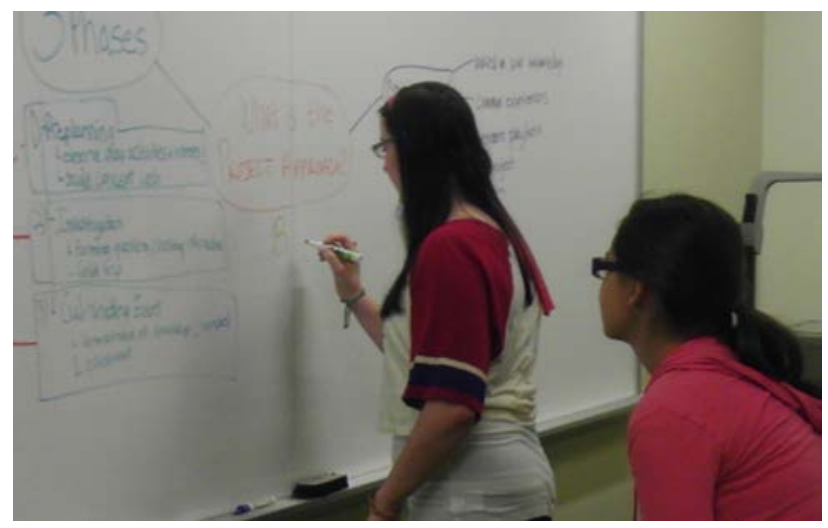

Figure 5. Teacher candidate leads the development of a Project Approach topic web

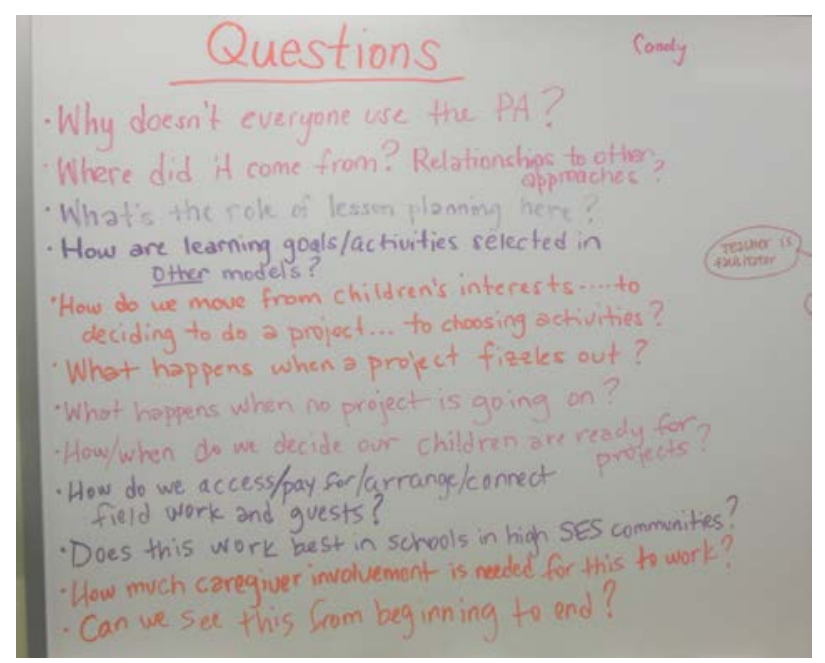

Figure 6. Candidates' initial questions about the Project Approach

The candidates' initial list of questions also reflected early attempts by the teacher candidates to evaluate this new information in light of social justice issues that had been highlighted throughout their prior coursework (Questions such as Does this work best in schools in high SES communities?). This work would continue in the next phases as the candidates explored their commitment to addressing diversity.

\subsubsection{Phase 2.}

As indicated in Table 1, the candidates took responsibility for investigating their questions and areas of interest for most of weeks 3 to 25. Following their initial visit to preschool classrooms, the candidates came together to revisit, reorganize, and expand upon their initial questions. The candidates reorganized their questions into topical groups; they gradually realized that some of their questions were general in nature, while others pertained to 
specific phases or practices of the Project Approach. The

result of this work is presented in Table 3.

Table 3. Teacher candidate questions for investigation

\begin{tabular}{|l|l|}
\hline Topic & Questions \\
\hline \multirow{5}{*}{ General questions } & What is the role of lesson planning? \\
& What happens during the rest of the day when not working on a project? \\
& How do we access/pay for/arrange/connect field work and guests? \\
& How much caregiver involvement is required? \\
& What is the role of collaboration with administrators? \\
& How does one school manage many projects? \\
& How does the Project Approach work with children with special needs? \\
& Will the approach work in low-SES communities and the schools that serve them? \\
\hline \multirow{3}{*}{ Phase One } & How do we decide when children are ready for a project? \\
\hline \multirow{3}{*}{ Phase Two } & How do we move from children's interests...to deciding to do a project? \\
& How do we assess learning while doing phase one activities? \\
\hline \multirow{3}{*}{ Phase Three } & How do we move from the topic/focus of a project to choosing activities? \\
& What role does lesson planning take in this process? \\
\hline & How do we assess children while they are doing field work? \\
& What happens when a project fizzles out? \\
\hline & Who does all of the planning for culminating events? \\
& How do we decide whether a project has been successful? \\
& How do we assess children's learning as a whole? \\
\hline
\end{tabular}

The candidates were simultaneously engaged in multiple levels of questioning. They expressed curiosity about how to work with children and assess their learning, but they also showed an interest in broader issues (e.g., implementation, the role of administrative support, and the relationship of project work to the rest of the day's schedule and routines). They also expanded their questioning regarding diversity and social justice, including questions about the use of the Project Approach with children with special needs, and in schools and communities with few resources or access to settings in which to safely conduct fieldwork. Next, the candidates worked in pairs to brainstorm methods for answering their questions, as well as identify potential resources that could assist in their investigation. The results were shared and combined into a master list, presented in Table 4.

Table 4. Methods and resources for investigation of the Project Approach

\begin{tabular}{l|}
\hline Methods \\
\hline - Interview teachers about their experiences \\
- View projects in action \\
- Speaking with school administrators \\
- Examining children's assessment portfolios \\
- Examining teachers' lesson plans \\
- Interview caregivers regarding their involvement in school activities \\
and as topic-area experts \\
- Observations in multiple classrooms \\
- Read resources and studies \\
- Visit schools where other approaches are in use
\end{tabular}

Relatively few of the candidates' questions addressed documentation or adult-child interaction. Initially, the candidates stated that they felt quite confident entering the classrooms. They anticipated that project-based adultchild interactions would be much more 'tangible' and easier to observe than activities they previously planned for infants and toddlers because they saw these interactions in preschool as more directly serving the overall project. They anticipated having an easier time working with active, engaged, and verbal preschoolers than they had with infants and toddlers. Furthermore, having already seen examples of projects and observed project work in action, as well as having conducted initial readings about aspects of the Project Approach, the candidates felt prepared to engage in supervised interaction with preschoolers within ongoing projects. The candidates' initial questions regarding transitions between the phases represented practical issues, while their deeper questions regarding pedagogy and classroom management would emerge after week 11, when they began their student teaching experience.

The investigation proceeded over subsequent weekly visits to FXW. The teacher candidates each observed classroom activities and children, met with their assigned mentor teachers and administrators, and participated in various ongoing aspects of project work in their
Available resources

- Cooperating teachers and administrators

- Interactions with children

- Classroom activities

- Internet and library resources

- Video documentation of a project

- Class readings, including effectiveness studies

- Caregivers

- Project archive

- Project Approach materials (i.e., publications and videos)

- Professional development

classrooms. They also used internet and library resources and viewed video documentation of projects, as well as completing brief interviews with their co-teacher educators. Throughout, the candidates represented their emerging understanding of the Project Approach. In the context of this work, representation was viewed as any product that provided insight into candidates':

a) knowledge of the Project Approach, as evidenced by the answers they reached and represented in seminar meetings;

b) progress on the module objectives and their fieldbased assignments;

c) increased effectiveness as developing teachers, as assessed by the ratings of supervising Loyola faculty.

Faculty and candidates met weekly for 90-minute reviews of progress on the investigation during weeks 310 , and for 45-minute reviews during weeks 11-25. These served as discussion sessions, Project Approach workshops, and collaborative planning sessions, providing an opportunity to examine and reflect on candidates' progress in exploring their questions. These meetings served to focus faculty visits to each classroom on addressing candidates' areas of individual interest. Faculty observed and provided direct feedback to candidates during every one of these visits to the classrooms through week 10. Faculty gave the candidates short field-based 
assignments designed to increase their skills at planning/assessing developmentally appropriate learning environments, observing and practicing supportive adultchild interaction, and assessing children's skills and developmental levels. The candidates completed these assignments while simultaneously exploring the Project Approach. During the spring sequence (Weeks 11-25) each candidate was visited six times, with formal evaluation conducted on three visits and formative feedback provided throughout.

As previously mentioned, the candidates were observed by Loyola faculty and assessed during project work in order to provide feedback and targeted support for their interactions with children. They were observed by both faculty and classroom teachers as they led small and large group activities, including centers, morning meetings, whole-group story reading, and some child-directed play. They also facilitated the development of topic webs and worked alongside children already engaged in projects. During student teaching in the spring, each of the four candidates at some point had the opportunity to guide project learning through all three phases. Guiding children through complete projects (on such topics as parks in the neighborhood and spring), served as one of the culminating activities of phase 3 .

\subsubsection{Phase 3}

Beginning with the spring student teaching semester (at which point the field-based commitment increased to 3 days per week for weeks 11 to 25), the teacher candidates began to take greater responsibility for daily project work. Their investigation and reflection continued during this time, during which they took on a supported teaching role. Loyola faculty observed candidates on a biweekly basis, including pre, midterm, and post assessment observations using the clinical evaluation tool with Project Approach adaptations (a small portion of which was displayed in Table 2).

While weekly meetings with faculty continued to provide workshop time and check-ins on topic of interests, more formal debriefing sessions were held at the midpoint and end of the learning module, in order for faculty to assess progress on the overall investigation and assist candidates in considering ways they might represent what they had learned. Prior to student teaching, candidates' early discussions of possible culminating events produced few ideas. However, through class discussions and feedback sessions they came to recognize that the experience of facilitating project learning with children was a primary culminating event of the project. Their investigation allowed each candidate to test individual assumptions, ask questions, and explore projects in a supported role prior to assuming responsibility for guiding preschoolers' projects. They proceeded to document their work with children, collecting artifacts, taking photos/making video recordings, and writing reflections across the Project Approach phases.

The candidates proposed using the Project Approach as a theme for presentations to other undergraduate students as a way of generating interest in the field of early childhood education and planting seeds of mentorship within the ECSE program. They planned informational sessions at which to share their experiences and demonstrate project learning to freshman-level education majors. Two such sessions were held at the end of the learning module, which coincided with the end of candidates' junior year in the ECSE program. During the first session, they introduced the ECSE program and shared their field experiences with incoming freshmen who had expressed an interest in working with young children, describing both the successes and challenges they experienced during their junior year modules.

For the second session, the candidates led a professional development session on inquiry learning in early childhood education and their experiences with the Project Approach to an audience of teacher education majors and faculty. This session displayed the candidates' growth as developing professionals and as leaders, as well as their interest in service to the profession of early childhood education while simultaneously demonstrating their notably deeper understanding of the Project Approach. The candidates engaged the participants in activities to demonstrate how early childhood educators utilize engaging and flexible learning materials. They then shared the Project Approach as an example of childdirected, inquiry-based learning, and highlighted areas of alignment between the Project Approach and developmentally appropriate practice (DAP; [20]). Finally, the candidates shared ways in which progress monitoring and targeted literacy activities may be integrated into Project Approach activities, as well as into other activities in classrooms where project learning takes place. Figure 7 to Figure 9 show the teacher candidates presenting on the Project Approach and its phases, sharing samples of their instruction, documentation, and assessment during projects conducted at FXW.

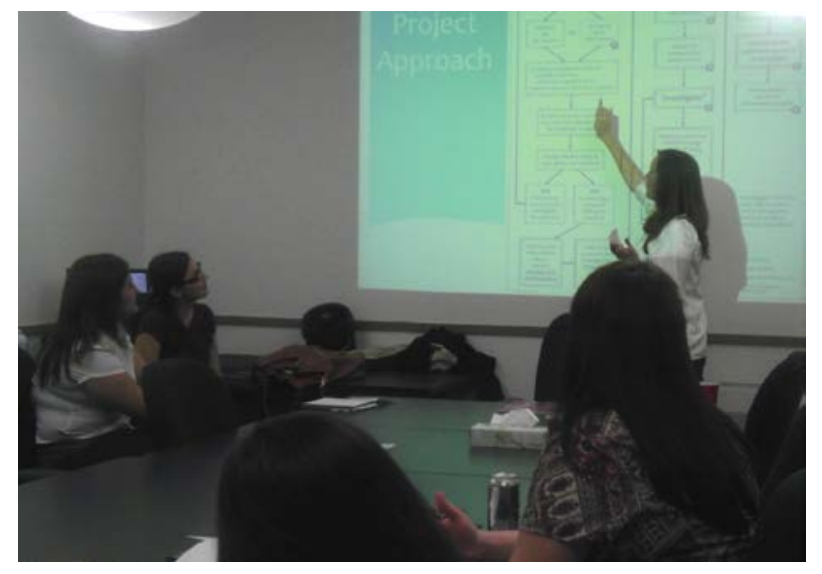

Figure 7. Undergraduate teacher candidates present on the Project Approach

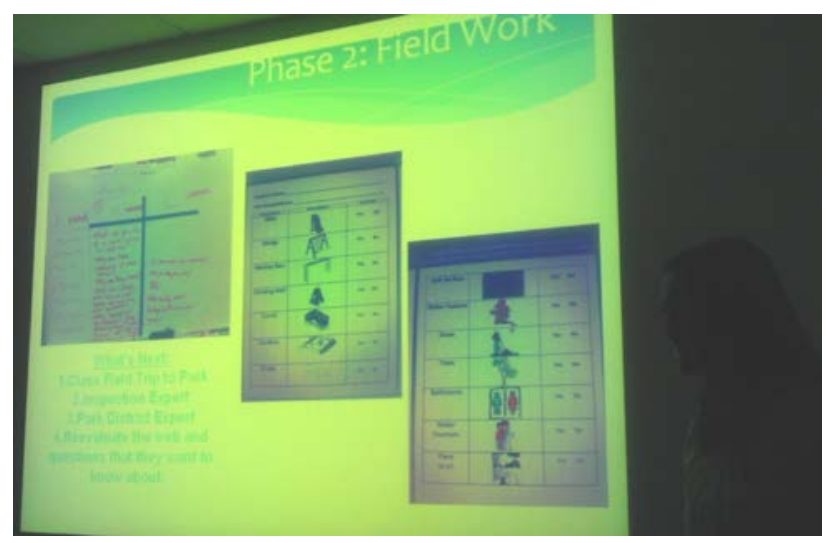

Figure 8. Teacher candidate presents examples of phase two project learning during student teaching 


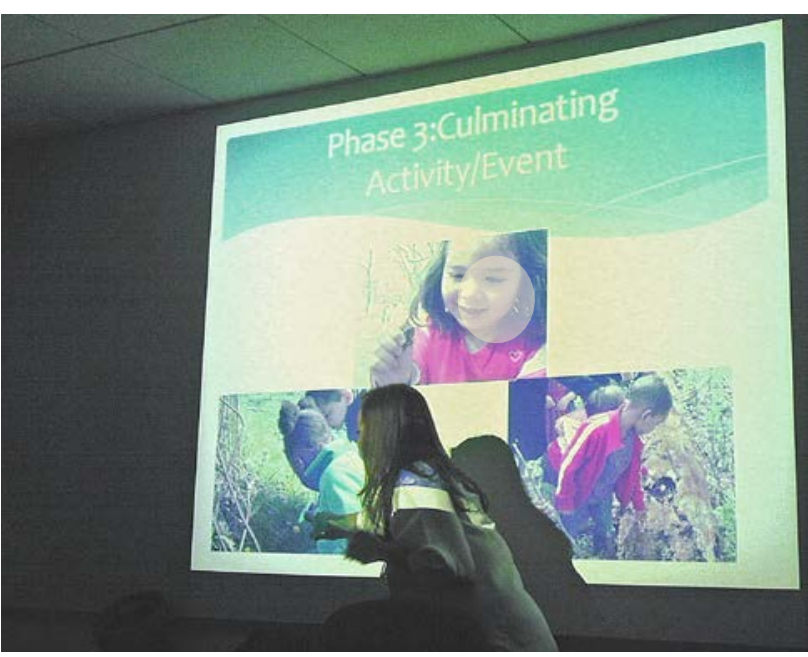

Figure 9. Teacher candidate presents examples of phase three project learning conducted with FXWers during student teaching

\section{Outcomes}

The four teacher candidates who participated in this pilot increased their knowledge of the Project Approach through guided investigation and university classroombased learning activities. They observed and modeled facilitation of small and large group activities (including building topic webs, generating questions, and leading a variety of learning activities), and developed (over an extended period of time) their skills in guiding children through the phases of projects. While other researchers have reported varying degrees of success in transferring successful professional development experiences in to practice (e.g., [5]), the candidates here experienced project-based learning firsthand in their classrooms throughout, later leading projects themselves with a goal of positively impacting young children's learning. These experiences served to narrow the preparation-to-practice gap, and their positive experiences reinforce the need for contextually-situated professional development focused on the Project Approach [24].

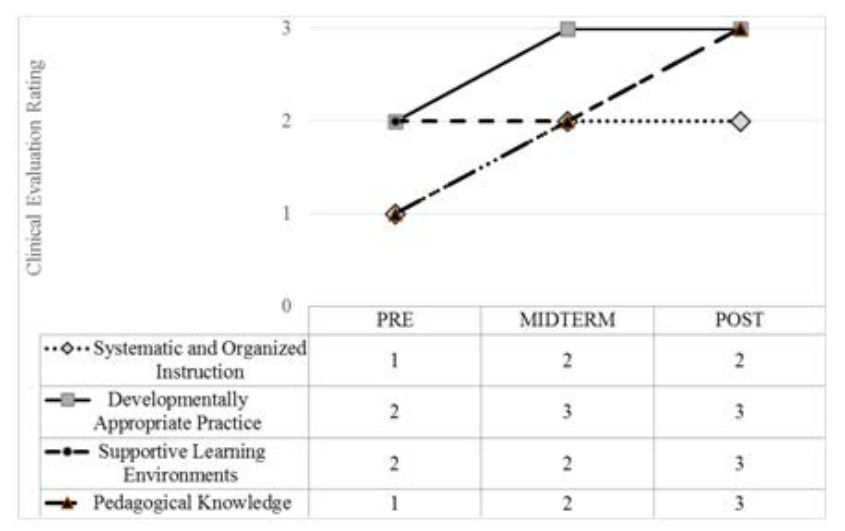

Figure 10. Typical candidate progress during student teaching

As in prior research, this investigation provided an authentic and rich context within which to assess candidates' skills. Because of the emergent nature of projects, it was necessary to focus assessments of candidates' teaching on observable skills that did not depend upon any particular project's stage of completion. In this sense, the universal clinical evaluation tool was well-matched to the student teaching sequence. While faculty had originally intended to assess candidates over the course of a single project, it eventually became clear that opportunities would be available to assess candidates through sampling various ongoing projects rather than by following the candidates longitudinally through a single project. This highlighted the need for increased teacher participation in candidate evaluation activities. Figure 10 displays a typical pattern of progress on key indicators of candidates' teaching effectiveness during weeks 11-25. Ratings of 2 represent acceptable scores for juniors, while 3 is a target rating for senior ECSE majors in their second (full-time) student teaching placement.

The candidates encountered typical implementation issues (e.g., adaptations for diverse children, supporting children's interests, deciding when a project should be discontinued) and relied on the support of faculty and preschool teachers to problem-solve and improve their emerging skills as teachers. Throughout this experience, candidates generated and answered practical, philosophical, and ethical questions regarding their emerging pedagogical skill. For example, they worked with their mentor teachers to utilize community resources for projects (and explore the community surrounding the school), as well as participate in teacher meetings during which projects were shared, planned, and refined. These opportunities would have been unavailable had candidates participated solely in university-based activities or simulations (again reinforcing the advantages of fieldsituated learning experiences). While engaged in this work, the candidates engaged in continuous representation that documented their work and used existing school-based assessment systems to evaluate the development and learning of preschoolers. They also increased the awareness and understanding of other faculty members, staff, and candidates who were previously unfamiliar with the Project Approach.

Prior research on the Project Approach provides little information regarding participating teachers' success in translating their preparation experiences into projects once those teachers returned to their schools to implement aspects of the Project Approach. This reinforces the question of how to best support implementation of the approach in the field. The advantages of an inquiry-based approach with modeling and implementation support offered several key learning opportunities. First, this model allowed teacher candidates to engage in project learning that was developmentally appropriate for adult learners. While the candidates were all working toward developing universal competencies of effective instruction with preschoolers, they did so while investigating individual and shared questions about the approach while actively engaged in the classrooms for an extended span of time. Next, while this project was conducted in collaboration with a school where the Project Approach was used, this did not insulate candidates from various barriers to implementation (such as specific candidate skill deficits, issues in collaboration, or practical concerns related to specific child-initiated projects). Rather, these challenges all evolved into project-related questions for candidates to investigate and address under faculty supervision (rather than remaining hypothetical until some future point of implementation). In more traditional professional development, practitioners must address these 
concerns upon returning to their own schools/centers, where essential supports for implementation may be lacking (or where colleagues and administrators may not use or even understand the Project Approach). Finally, the extended, field-based approach used here allowed candidates sufficient time to develop their knowledge and skills. As an example, they initially had difficulty grasping the idea that topic web development is both an investigatory process and instructional activity for children with limited understanding of a topic. Given time to observe, investigate, and participate, candidates had firsthand experiences that illustrated the differences between simply representing concepts and relationships visually and that of building a map that includes both prior knowledge and questions to investigate and helps to drive the subsequent investigation. Eventually, they were able to reap the benefits of this understanding as they applied it to their work with children.

\subsection{Candidate reflections}

Faculty led a final debriefing session with candidates in order to allow them to self-assess their overall progress on the investigation questions. The candidates represented some of their learning in the form of recorded video journals. Themes which emerged from a content analysis of these journals are presented below.

Theme \#1: Evidence of child-directed inquiry

The candidates shared numerous examples from their classrooms, citing specific examples in which teacher supported children's approaches to inquiry. A journal excerpt representing this theme are shared below, in which Candidate 1 describes the ways in which her mentor teacher supported children's questioning and independent exploration.

Candidate 1: In my room they started a new unit at $A B C$ School talking about doctors and what does that entail, and during the last few weeks I took part in the exploration process of the children. Them learning where it is that they have to take shots, where they check your blood pressure and any little question that the children would have they would always ask the teacher. The teacher would not answer the questions directly, but instead said well what do you think? Or how can we find out? And that's just great. Yeah, the teacher is there and the teacher is there to help the children learn and everything, but the teacher wasn't giving them the answers. The children were being directed for them to think...where could they find the answers or what other resources are available and the children would find out the answer through themselves and the teacher would just guide them in.

Theme \#2: Benefits of the Project Approach

This theme is reflected in the quote below from Candidate 2, who shares some of the ways in which she feels this approach benefits young children.

Candidate 2: To be immersed in that I guess I thought it was the best thing in the world. It's just so child directed, child centered and I think it's something that will really serve the kids in their future because they are getting so many real life experiences and they are just being their own facilitators of their learning. So I think it's going to be very valuable for them.

Theme \#3: Changes in perception
All of the candidates shared examples of the ways in which their experiences changed their view of the Project Approach. Candidate 4, for instance, discussed her initial skepticism about the approach and how her experiences challenged that initial perception.

Candidate 4: It just seemed very abstract and unrealistic to me, but now seeing this at FXW the children are guiding their own learning, they are coming up with these questions, they are seeking answers through these questions through their play. Coming from this background rooted in direct instruction it was so different to see the Project Approach because it was child initiated and child directed and to see the kids really get into it. It was amazing to see it in action you know having the kids really take charge, really getting involved in their project and their education. It makes a lot of sense, the Project Approach because as teachers you can design activities centered around learning standards, but the topics and activities all come from the things the children want to do that the children are interested in. And obviously they're going to get more involved and interested and engaged in the activities because it's stuff they want to do - it's stuff that they came up with.

To summarize, the outcomes of this study fell into three categories. First, evidence suggested that the experiences of candidates during this project led to an understanding of not only Project Approach features and teaching strategies, but of a variety of implementation challenges and how to address them. Next, the candidates showed an understanding and appreciation for the Project Approach as a form of inquiry learning, and recognized the importance of child-directed inquiry. Finally, the metaproject provided an appropriate context for the candidates to develop essential teaching skills evaluated as part of their student teaching experience.

\subsection{Limitations and Considerations for the Future}

Representation remains an aspect of this investigation requiring further development. In projects with young children, representation often takes place as children use the creative arts as a vehicle for expressing and sharing what they have learned through investigation, as well as continuing to explore topics via creative play. Prior to student teaching, the candidates valued and enjoyed expressing themselves artistically during various seminar activities; they represented their learning in many ways by revisiting their questions and drawing new maps, and by incorporating new knowledge into their written reflections and seminar assignments. However, they eventually struggled to develop new ways to represent their conceptual understanding of the Project Approach. Once they began applying this knowledge to practice, representation took on new meaning for them. For them, the most developmentally appropriate representation of Project Approach learning occurred during interactions with children and co-teacher educators in the field through creative and collaborative teaching acts and within ongoing projects themselves.

Lastly, the teacher candidates expressed the desire to conduct further investigation into the use of the Project Approach with children with special needs. Candidates made accommodations in their teaching throughout the ear 
for young children with a variety of learning needs, but reported that they struggled with individualizing project work so that it was both child-directed and developmentally appropriate for every individual while still providing sufficient opportunities for some children (particularly those with challenges related to behavior and early literacy) to develop critical competencies.

\section{Conclusions}

The Project Approach can be meaningfully and effectively integrated into early childhood teacher education. First and foremost, the Project Approach successfully served as a project topic; it met the requirements of an appropriate topic and was sustained for an extended period of investigation. Candidates in the ECSE program exercised critical thinking and creative problem solving throughout their investigation, as well as collaborating consistently with Loyola faculty and preschool educators and each other. Over an extended investigation period, they worked to solve complex applied and practical problems related directly to preschool teaching. In this program, essential conditions for the success of the learning module included sufficient time to observe and actively participate in Project Approach activities and to engage in supervised instruction with young children across all phases of the approach, as well as opportunities to explore pedagogical and implementation issues authentically during practice. This investigation of the Project Approach would not have been possible in the absence of deep, mutually-beneficial collaboration with a school in which the approach is fully integrated. This project not only enhanced candidates' appreciation of the approach, but it also served to increase candidates' effectiveness as early childhood educators as evidenced by improved ratings of teaching and adult child interaction over the course of the sequences. By investigating the approach as teachers would, and immediately applying their knowledge and skills to their work with children, teacher candidates engaged in a selfdirected and self-motivated project of their own which addressed complex essential questions about their roles as future educators.

\section{Acknowledgement}

This project was supported in part by the U.S. Department of Education, Office of Special Education Programs (OSEP) under a grant in Personnel Preparation in EI/ECSE (\#H325K120172).

\section{References}

[1] American Association of Colleges of Teacher Education (2010). $21^{\text {st }}$ century knowledge and skills in educator preparation. Available: http://www.aacte.org.

[2] Barrows, H. (1985). How to design problem-based curriculum for the pre-clinical years. New York: Springer Publishing.

[3] Barrows, H, \& Tamblyn, R. (1980). Problem-based learning: An approach to medical education. New York: Springer Publishing Company.
[4] Broderick, J., and Hong, S. (2011) "Introducing the cycle of inquiry system: A reflective inquiry practice for early childhood teacher development”. Early Childhood Research \& Practice. 13(2). [Accessed May 25, 2015].

[5] Bullard, J., and Bullock, J. (2002). "Modeling collaboration, indepth projects, and cognitive discourse: A Reggio Emilia and Project Approach course.” Early Childhood Research \& Practice. 4(2). [Accessed May 1, 2015].

[6] Chard, S. (1994). The Project Approach: A practical guide, I and II. New York: Scholastic.

[7] Darling-Hammond, L., Baratz-Snowden, J., \& National Academy of Education. (2005). A good teacher in every classroom: Preparing the highly qualified teachers our children deserve. San Francisco, CA: Jossey-Bass.

[8] Division for Early Childhood. (2014). DEC recommended practices in early intervention/early childhood special education 2014.

http://www.dec-sped.org/recommendedpractices. [Accessed April 10, 2015].

[9] Goos, M. (2004). "Learning mathematics in a classroom community of inquiry." Journal of Research in Science Teaching, 35, 258-291.

[10] Harada, V., Kirio, C., \& Yamamoto, S. (2008). Collaborating for project-based learning in grade 9-12. Columbus, $\mathrm{OH}$ : Linworth.

[11] Hatch, J.A., \& Benner, S. (2009). "From the editors: Positionings and possibilities for early childhood teacher education.” Journal of Early Childhood Teacher Education, 30, 91-92.

[12] Heineke, A.J., Kennedy, A.S., \& Lees, A. (2014). "Preparing early childhood educators for the culturally and linguistically diverse classrooms and communities of Illinois." Early Childhood Research \& Practice, 15(2). October 2013.

[13] Helm, J., \& Katz, L. (2011). Young investigators: The Project Approach in the early years. New York, NY: Teachers College Press.

[14] Hmelo-Silver, C. (2004). "Problem-based learning: What and how do students learn?” Educational Psychology Review, 16(3), 235266.

[15] Katz, L. (1995). Talks with teachers of young children: A collection. Norwood, NJ: Ablex.

[16] Katz, L. (2000). Engaging children's minds: The project approach. Norwood, NJ: Ablex.

[17] Katz, L., \& Chard, S. (2000). Engaging children's minds: The project approach (2nd ed.). Stamford, CT: Ablex.

[18] Kennedy, A., \& Heineke, A. (2014). "Re-envisioning the role of universities in early childhood teacher education: Community partnerships for $21^{\text {st }}$ century learning." Journal of Early Childhood Teacher Education, 35(1), 226-243.

[19] Moursund, D. (2003). Project-based learning using information technology $\left(2^{\text {nd }} e d.\right)$. Eugene, OR: International Society for Technology in Education.

[20] National Association for the Education of Young Children (2009). Developmentally appropriate practice in early childhood programs serving children from birth through age 8. http://www.naeyc.org/files/naeyc/file/positions/PSDAP.pdf. [Accessed May 22, 2015].

[21] Riojas-Cortez, M., Alanis, I., \& Bustos Flores, B. (2013). "Early childhood teachers reconstruct beliefs and practices through reflexive action.” Journal of Early Childhood Teacher Education. 34 (1), 36-45.

[22] Ryan, A.M.,Ensminger, D., Heineke, A., Kennedy, AS., Prasse, D., \& Smetana, L. (2014). "Teaching, Learning, and Leading with Schools and Communities: One urban university re-envisions teacher preparation for the next generation”. Issues in Teacher Education, 22(2), 139-153.

[23] Seo, K.; Templeton, R., \& Pellegrino, D. (2008). "Creating a ripple effect: Incorporating multimedia-assisted project-based learning in teacher education.” Theory into Practice. 47(3), 259265.

[24] Vasconcelos, T. (2007). "Using the Project Approach in a teacher education practicum.” Early Childhood Research and Practice, $9(2)$.

[25] Wiggins, G., \& McTighe, J. (2005). Understanding by design (2nd ed.). Washington, DC: Association of Supervision and Curriculum Development. 